\title{
Responsabilidad patrimonial del Estado por funcionamiento anormal de la Administración de Justicia (Corte Suprema)
}

\author{
Comentario de Pablo Soto Delgado*
}

Santiago, dos de junio de dos mil quince.

$[\ldots]$

Primero: Que en estos autos Rol N 4390-2015 se interpuso en contra del Fisco de Chile demanda de indemnización de perjuicios derivados de la privación de libertad que sufrió el demandante, Jorge Espinoza Marfull, ocurrida entre los días 7 a 9 de mayo de 2011, a consecuencia del actuar de órganos del Poder Judicial que califica de negligente al haber emitido una orden de detención en su contra con error en los datos -número de la causa sobre la cual recaía- y que tras el sobreseimiento definitivo dictado en el respectivo proceso, no se advirtió que dicha orden de privación de libertad permaneció vigente, la misma que se materializó al ser detenido en el Aeropuerto Internacional de Santiago cuando se prestaba a viajar al extranjero junto a su cónyuge, siendo trasladado en un carro de Gendarmería a la ciudad de Concepción para comparecer en una causa criminal por giro doloso de cheques terminada hace quince años al haberse pagado la totalidad de lo adeudado.

De conformidad al artículo 782 del Código de Procedimiento Civil, se ha ordenado dar cuenta del recurso de casación en el fondo deducido por el Consejo de Defensa del Estado en contra de la sentencia de la Corte de Apelaciones de Concepción que, revocando lo decidido en primera instancia, resolvió acoger la demanda, condenando al Fisco de Chile a pagar por concepto de daño moral la suma de $\$ 15.000 .000$ al actor y \$5.000.000 a su cónyuge, Marta Meneses Garfias.

SEgundo: Que el recurso de nulidad acusa que la sentencia impugnada ha incurrido en errores de derecho al desestimar la excepción de falta de legitimación pasiva opuesta por el Fisco de Chile.

Denuncia, en primer término, la infracción de los artículos 1, 4 y 42 de la Ley $\mathrm{N}^{\circ} 18.575$ sobre Bases Generales de la Administración del Estado. Sostiene que el Poder Judicial no es un órgano de la Administración del Estado o Administración Pública y, por tanto, el Estado no es responsable de la actuación de sus miembros, de manera que tales normas no son aplicables a estos últimos.

\section{$[\ldots]$}

* Abogado. Profesor de Derecho Administrativo y Doctorando en Derecho, Facultad de Derecho, Universidad Diego Portales, Santiago, Chile. Correo electrónico: pablo.soto@mail.udp.cl. 
A continuación, el recurrente denuncia la transgresión de los artículos 11, 13, 324, 325, 326, 327 y 328 del Código Orgánico de Tribunales, en cuanto consagrarían el estatuto de la responsabilidad tanto penal como civil de los jueces en el ejercicio de sus funciones, normas que prescriben que todo juez que incurra en delito o cuasidelito será además civilmente responsable de los daños que hubiere irrogado a terceros a causa de su conducta. Pone de manifiesto que de conformidad a lo dispuesto en este último texto legal, los únicos que tienen responsabilidad funcionaria propiamente tal con la dictación o no de resoluciones judiciales y en las órdenes que en función de ellas se impartan a las reparticiones públicas, son los jueces y, en consecuencia, para hacerla efectiva se debe dirigir la acción directamente contra ellos y ante el tribunal que sea competente para su conocimiento.

Destaca que el contenido o efectos de las resoluciones emitidas por nuestros tribunales de justicia no puede comprometer la responsabilidad del Fisco a menos que se cumpla cabalmente con los requisitos previstos en la Constitución Política de la República en su artículo $19 \mathrm{~N}^{\circ} 7$ letra i), precepto que establece la única hipótesis que obliga al Estado a indemnizar un daño causado por un error judicial.

\section{[...]}

Tercero: Que el tribunal de alzada decidió acoger la pretensión indemnizatoria de los demandantes teniendo en consideración que la responsabilidad del Estado es de carácter genérica, pues emana de la naturaleza misma de esa actividad estatal en cuanto organización jurídica y política de la comunidad, en las variadas acciones que debe desarrollar en el ámbito de las funciones que le corresponde llevar a cabo para el cumplimiento de tales funciones y deberes reconocidos en el artículo $1^{\circ}$ de la Carta Fundamental, y para la cual debe hacer uso de todas las potestades y medios jurídicos y materiales que ella le otorga (considerando cuarto de la sentencia recurrida).

$\mathrm{Y}$ añade que no habiendo una norma particular que regule específicamente esta clase de responsabilidad extracontractual del Estado, "como lo hace el actual artículo 42 de la Ley de Bases respecto de la generalidad de los órganos de administración, se debe aplicar necesariamente la de los artículos 2314 y siguientes del Código Civil, entendiendo que el Estado es una persona jurídica capaz de cometer delito o cuasidelito y por lo mismo obligado a indemnizar por los daños ocasionados con dolo o culpa de las personas que actúan en su nombre o representación" (considerando noveno de la misma sentencia).

Cunto: Que como reiteradamente ha venido sosteniendo esta Corte acerca de qué ocurre con los daños causados por aquellos órganos estatales que han sido expresamente excluidos de las normas legales que atribuyen responsabilidad al Estado por falta de servicio, dicha situación ha de resolverse acudiendo al derecho común en materia de responsabilidad extracontractual, esto es, los artículos 2314 y siguientes del Código Civil. En otras palabras, en ausencia de norma legal especial, le asiste al Estado el deber 
de reparar los daños ilícitos causados por sus órganos sobre la base de la normativa de responsabilidad extracontractual del Código Civil, lo que incluye a los jueces cuando se ha verificado un "funcionamiento anormal" de la Administración de Justicia, desde que estos actúan en ejercicio de una función pública.

Asimismo, si ha existido falta personal se compromete igualmente la responsabilidad del Estado cuando aquella se comete con ocasión del servicio, esto es, de conformidad al artículo 2320 del Código Civil por el hecho ajeno de aquellos por quienes el Estado debe responder.

Por consiguiente, cabe descartar la primera alegación del recurso de casación en orden a que el Estado se encuentra exento de responsabilidad por las actuaciones de los miembros del Poder Judicial.

$[\ldots]$

Sexto: Que si bien el Código Orgánico de Tribunales se refiere a la responsabilidad de los jueces por delitos funcionarios, señalando que éstos serán personalmente responsables de los daños que se provoquen a terceros, ello no obsta a que haya acción en contra del Estado, pudiendo el afectado dirigirse indistintamente en contra del Estado o del funcionario, según lo estime conveniente, si se configura lo que se denomina cúmulo de responsabilidades de acuerdo a lo señalado precedentemente con motivo de la falta personal.

SÉPtimo: Que, por otra parte, cabe consignar que tampoco procede en este caso la indemnización por error judicial que prevé el artículo $19 \mathrm{~N}^{\circ} 7$ letra i) de la Constitución Política de la República, desde que ésta supone un sometimiento a proceso o condena que haya sido consecuencia de una sentencia injustificada o errónea, circunstancias que no concurren en la especie, puesto que la falta que se atribuye a la actividad judicial se hace consistir en la materialización de una orden de aprehensión vinculada a una causa criminal terminada quince años antes, por lo que no corresponde a una resolución que someta a proceso ni a un fallo condenatorio.

$[\ldots]$

Undécimo: Que acorde con lo expuesto el recurso de casación en el fondo no podrá prosperar al adolecer de manifiesta falta de fundamento.

Por estas consideraciones y de conformidad además con lo dispuesto en el artículo 782 del Código de Procedimiento Civil, se rechaza el recurso de casación en el fondo deducido en lo principal de fojas 237 en contra de la sentencia de diecinueve de enero de dos mil quince, escrita a fojas 233.

Rol No 4390-2015. 


\section{Comentario}

Entre los remedios frente a la falibilidad del Sistema de Justicia criminal, se hallan los mecanismos indemnizatorios que a través de una compensación económica resarcen el perjuicio producido al imputado por el error en las resoluciones judiciales o a través de la investigación previa. El primero se encuentra regulado en el artículo $19 \mathrm{~N}^{\circ} 7^{\circ}$ i) de la Constitución e institucionaliza en el ordenamiento jurídico nacional la denominada responsabilidad del Estado Juez ${ }^{1}$. La segunda herramienta se halla en el artículo $5^{\circ}$ de la Ley Orgánica Constitucional del Ministerio Público y establece la responsabilidad del Estado por las conductas de dicho órgano. En ambos casos, el estándar de procedencia de la indemnización es la existencia de conductas públicas "injustificadamente erróneas o arbitrarias".

Con escasas excepciones ${ }^{2}$, la doctrina chilena parecía haber entendido que la única hipótesis para hacer responsable patrimonialmente al Estado Juez en nuestro ordenamiento era el error judicial. Este fue uno de los argumentos del Fisco en el caso cuyo fallo se comenta. En contra de esta idea, la Tercera Sala de la Corte Suprema acaba de ampliar la responsabilidad patrimonial del Estado Juez hacia supuestos que no se encuentran expresamente tasados legal ni constitucionalmente. Como se sabe, de acuerdo al texto constitucional, la indemnización exige la existencia de una "resolución” judicial, es decir, requiere que el error se presente en el ejercicio de la función jurisdiccional de resolver conflictos sometidos a su conocimiento. No existe una disposición jurídica que tenga por finalidad directa indemnizar por el funcionamiento anormal de la Administración de Justicia, como sí acontece, por ejemplo, en el caso español donde el supuesto se encuentra contemplado en el artículo 121 de la Constitución de 1978 y en el artículo 292 (1) de la Ley Orgánica del Poder Judicial.

El funcionamiento anormal de la Administración de Justicia como título de imputación de responsabilidad patrimonial al Estado es un concepto jurídico indeterminado que incluye situaciones como la dilación indebida, funcionamiento irregular en los procedimientos judiciales o falta de coordinación entre órganos, situaciones que no pueden reconducirse al error en las resoluciones judiciales ${ }^{3}$ sino que a un equivalente a la falta de servicio administrativa, aunque cometida por órganos judiciales. En virtud de esa similitud, la Corte Suprema, para resolver el recurso del Fisco, ha replicado un razonamiento que aplica permanentemente cuando se persigue la responsabilidad por actuaciones de las Fuerzas Armadas: que a falta de regulación expresa, es necesario acudir a las reglas del derecho común contenidas en los artículos 2314 y siguientes del Código

${ }^{1}$ Carmona, C., "La responsabilidad del Estado-Juez. Revisión y proyecciones", en Revista de Derecho Público, Vol. 68, 2004, pp. 307-356.

${ }^{2}$ Al respecto, Montero, C., "Notas sobre la responsabilidad del Estado por el deficiente funcionamiento del sistema de administración de justicia”, en Ars Boni et Aequi, Año 9, No 2, 2013, pp. 145-171.

${ }^{3}$ Cobreros, E., "Funcionamiento anormal de la Administración de Justicia e indemnización", en Revista de Administración Pública, No 177, septiembre-diciembre 2008, pp. 31-69. 
Civil. Siguiendo la tesis del profesor Pierry ${ }^{4}$, la culpa civil es un equivalente funcional de la falta de servicio y, por lo tanto, procede acudir a ella para integrar lagunas.

Tres conclusiones se siguen de la sentencia comentada. En primer término, que la Corte ha incorporado una nueva regla, según la cual procede atribuir al Fisco la responsabilidad patrimonial del Estado Juez, argumentando como título de imputación el anormal funcionamiento de la Administración de Justicia -como actividad distinta de la resolución de causas sometidas a su conocimiento- fundándose en normas comunes. En segundo lugar, que en el Derecho Público es posible esgrimir el siguiente principio de interpretación: la regulación expresa y restringida de una materia -en la especie, la responsabilidad del Estado Juez en la hipótesis de error judicial del artículo $19 \mathrm{~N}^{\circ} 7$ letra i) de la Carta- no puede significar que otros supuestos no contempladas se encuentren excluidos. La Corte no se encuentra, pues, vinculada positivamente al principio de juridicidad ${ }^{5}$. Por ello, y como tercera conclusión, al tratarse de una fórmula general de responsabilidad patrimonial del Estado, parece posible aplicar esta tesis al funcionamiento anormal de cualquiera de los órganos constitucionalmente autónomos, a pesar de que no exista tal regulación en la Carta Fundamental o en sus respectivas leyes orgánicas constitucionales, tornando irrelevante la actividad normativa en la materia.

\footnotetext{
${ }^{4}$ Pierry, P., "Responsabilidad extracontractual del Estado por los delitos cometidos por sus funcionarios", en Revista de Derecho de la Pontificia Universidad Católica de Valparaíso, No 7, 1983, pp. 283-306.

${ }^{5}$ De Otto, I., Derecho Constitucional Sistema de Fuentes, Ariel, Barcelona, 2012, p. 158.
} 